Pesq. Vet. Bras. 31(3):239-243, março 2011

\title{
Tristeza parasitária bovina no Sertão da Paraíba ${ }^{1}$
}

\author{
Valéria M. de M. Costa ${ }^{*}$, Alberto L. Rodrigues², João M. de A. Medeiros², \\ Marcelo B. Labruna ${ }^{3}$, Sara V.D. Simões ${ }^{2}$ e Franklin Riet- Correa ${ }^{2}$
}

\begin{abstract}
Costa V.M.M., Rodrigues A.L., Medeiros J.M.A., Labruna M.B., Simões S.V.D. \& Riet-Correa F. 2011. [Cattle tick fever in the semiarid region of the Brazilian state of Paraiba.] Tristeza parasitária bovina no Sertão da Paraíba. Pesquisa Veterinária Brasileira 31(3):239-243. Hospital Veterinário, Centro de Saúde e Tecnologia Rural, Universidade Federal de Campina Grande, Campus de Patos, 58700-970 Patos, PB, Brazil. E-mail: valery.medeiros@ hotmail.com

Twenty four outbreaks of cattle tick fever are reported in the semiarid region of Paraiba known as Sertão. Eighteen outbreaks were caused by Anaplasma. marginale, two by Babesia bigemina, and two by mixed infection of $A$. marginale and Babesia sp. In other two outbreaks of babesiosis the species of Babesia was not identified. Outbreaks occurred from August 2007 to October 2009, however with a concentration of the outbreaks at the end of the rainy period and beginning of the dry period in each year. Twenty two outbreaks affected adult cattle and two affected calves approximately 11 months-old. Three outbreaks affected Bos taurus indicus cattle, of the Nelore and Gir breeds. In 21 outbreaks Holstein, Brown Swiss and crossbred of these breeds with Bos taurus indicus cattle were affected. It is concluded that in the sertão of Paraíba there are areas of enzootic instability for cattle tick fever occurring outbreaks at the end of the rainy season, mainly in hilly areas of the Borborema region, and in wet areas of some river basins, including Rio do Peixe, Rio Piranhas and Rio Espinharas.
\end{abstract}

INDEX TERMS: Anaplasmosis, babesiosis, ticks, Rhipicephalus (Boophilus) microplus, semiarid.

RESUMO.- Descrevem-se 24 surtos de tristeza parasitária bovina no sertão paraibano, sendo 18 de anaplasmose por Anaplasma margimale, dois de babesiose por Babesia bigemina, dois por Babesia não identificada e dois por infecção mista de A. marginale e Babesia sp. Os surtos ocorreram entre agosto de 2007 a outubro de 2009, porém, com uma concentração dos surtos no final do período chuvoso e início do período seco de cada ano, sendo 22 em animais adultos e dois em bezerros de aproximadamente 11 meses. Dois surtos ocorreram em bovinos da raça Nelore, um em animais da raça Gir e os 21 restantes ocorreram em animais das raças Holandês, Pardo Suiço e mestiços das

\footnotetext{
${ }^{1}$ Recebido em 8 de setembro de 2010. Aceito para publicação em 11 de outubro de 2010.

${ }^{2}$ Hospital Veterinário, Centro de Saúde e Tecnologia Rural (CSTR), Universidade Federal de Campina Grande (UFCG), Campus de Patos, 58700-970 Patos, PB, Brasil. E-mail: valery.medeiros @ hotmail.com

${ }^{3}$ Departamento de Medicina Veterinária Preventiva e Saúde Animal, Faculdade de Medicina Veterinária e Zootecnia, Universidade de São Paulo (USP), Av. Prof. Dr. Orlando Marques de Paiva 87, São Paulo, SP 05508-270, Brasil.
}

mesmas com zebuínos. Conclui-se que no sertão da Paraíba há áreas de instabilidade enzoótica, ocorrendo surtos de tristeza no final da época de chuvas, principalmente nas áreas de planaltos e serras da região da Borborema e em áreas úmidas como a Bacia do Rio do Peixe, Rio Piranhas e Rio Espinharas em que há a formação de microclimas favoráveis à sobrevivência do carrapato.

TERMOS DE INDEXAÇÃO: Anaplasmose, babesiose, Rhipicephalus (Boophilus) microplus, semiárido.

\section{INTRODUÇÃO}

Anaplasmose e babesiose são duas enfermidades distintas, que formam o complexo conhecido como tristeza parasitária bovina (TPB). A babesiose é causada pelos protozoários Babesia bovis e B. bigemina e a anaplasmose causada pela rickettsia Anaplasma marginale. Os três agentes são transmitidos pelo carrapato do boi, Rhipicephalus (Boophilus) microplus. A anaplasmose também pode ser transmitida de forma iatrogênica, transplacentária e por vetores mecânicos como moscas hematófagas, mutucas e culicídeos (Kessler 2001). 
A distribuição geográfica da TPB é limitada pela presença do carrapato vetor, que necessita de fatores ambientais favoráveis para completar seu ciclo biológico, variando em três áreas de ocorrência: 1) áreas livres, onde o carrapato não ocorre devido a condições climáticas que impedem o desenvolvimento do parasito; 2) áreas de instabilidade enzoótica, onde a ocorrência de uma estação seca ou fria impede o desenvolvimento da fase de vida livre do carrapato durante parte do ano. Assim, os bovinos passam uma época do ano sem ter contato com o parasita ou com poucos carrapatos, com isso não desenvolvem imunidade duradoura contra a doença. Nesses rebanhos há um significante risco de TPB devido à presença de suficiente número de animais susceptíveis que não foram infectados até os 7-10 meses de idade; 3) áreas de estabilidade enzoótica, nestas o carrapato está presente durante todo o ano, de forma que os bovinos são expostos a carrapatos infectados até os 7-10 meses de idade e durante o resto da vida, permanecendo imunizados. Nesses rebanhos, são raros os casos de doença clínica (Madruga et al 1993, Sacco 2002).

A TPB é um dos problemas sanitários que causa maior prejuízo econômico na pecuária bovina, que se traduz por altos índices de mortalidade e morbidade, com significativa redução na produção de carne e/ou leite, aborto e menor fertilidade nos animais afetados e altos custos com tratamentos e manejos especiais (Sacco 2001). A infecção é causada pelo desenvolvimento e multiplicação de Babesia spp. e A. marginale nas células sangüíneas e tem como sinais clínicos febre, anemia, icterícia (mais intensa e comum na anaplasmose), hemoglobinúria (na babesiose), parada ou redução da ruminação, sinais nervosos (característicos da babesiose por $B$. bovis, o mais virulento dos três agentes), anorexia e prostração (Dreher et al. 2005, Kocan et al. 2004, Souza et al. 2000).

O diagnóstico da TPB deve levar em consideração os dados epidemiológicos, sinais clínicos, lesões observadas à necropsia e principalmente exames laboratoriais. $\mathrm{O}$ diagnóstico clínico nos casos de suspeita de TPB tornase de suposição uma vez que os sinais clínicos podem ser confundidos com os de outras doenças. Desta forma o diagnóstico laboratorial, pela identificação do agente e o hematócrito, torna-se de extrema importância para a confirmação da doença e, consequentemente, para se fazer o tratamento específico dos animais e com isso, reduzir também os custos com medicação (Farias 2007).

Na Paraíba a prevalência de anticorpos para Babesia spp. foi estudada nas regiões de Campina Grande, Boqueirão e Cariri, determinando-se que a primeira é de estabilidade enzoótica enquanto que as outras duas são de instabilidade enzoótica (Madruga et al. 1994). Na região de Sertão Paraibano a situação da tristeza parasitária não é bem conhecida, mas surtos ocorrem nas regiões mais altas e nos leitos dos rios mais importantes da região (Costa et al. 2009). Nas áreas mais secas do sertão $R$. microplus não sobrevive durante o período de seca, mas tristeza parasitária pode ocorrer quando bovinos com carrapa- tos são introduzidos no início do período chuvoso e o parasita se multiplica durante esse período (Costa et. al 2009). O presente trabalho objetiva relatar surtos de TPB no Sertão Paraibano e descrever alguns aspectos epidemiológicos da doença.

\section{MATERIAL E MÉTODOS}

O estudo foi realizado na mesorregião do Sertão Paraibano, em propriedades onde ocorreram surtos ou casos isolados de TPB. Foram revisados protocolos de atendimento a campo e realizada leitura de lâminas de esfregaços sanguíneos de cada caso registrado no período de agosto de 2007 a setembro de 2009. O diagnóstico laboratorial foi realizado no Laboratório da Pós-Graduação no Hospital Veterinário da UFCG. Nas lâminas positivas para hematozoários foi calculado o percentual de parasitemia para cada agente encontrado. Amostras de sangue com anticoagulante foram processadas para determinação do volume globular pela técnica do microhematócrito. Após o diagnóstico as propriedades foram visitadas para aplicação de um questionário epidemiológico. Valores mensais de pluviosidade para o período de 1996 a 2009, mensurados no município de Patos, foram obtidos junto à Agência Executiva de Gestão de Águas do estado da Paraíba, a fim de se avaliar se a pluviosidade dos anos de 2007 a 2009 foram atípicas para a região, isto é, acima ou abaixo das médias dos anos pregressos.

\section{RESULTADOS}

Foram diagnosticados 24 surtos de tristeza parasitária bovina, sendo 18 de anaplasmose, dois de babesiose por $B$. bigemina, dois por Babesia não identificada e dois por infecção mista de Anaplasma marginale e Babesia sp.. O percentual de eritrócitos parasitados por $A$. marginale nos esfregaços sanguíneos variou de $1,8 \%$ a $80 \%$ e nos parasitados por B. bigemina variou de $2,06 \%$ a $5,21 \%$. Os valores do hematócrito, realizado em 16 animais, variaram de $8 \%$ a 18\%. Em 22 surtos foram afetados bovinos maiores de 18 meses e, em dois, bovinos de aproximadamente 11 meses de idade (Quadro 1). A porcentagem de morbidade variou de 0,5 a 40,4 (média: 11,6), com a porcentagem de letalidade variando de 0 a 100 (média: 35,8). Dois surtos ocorreram em bovinos da raça Nelore, um em animais da raça Gir e os 21 restantes ocorreram em animais das raças Holandês, Pardo Suiço e mestiços das mesmas com zebuínos.

Dos 24 surtos, 22 ocorreram no final do período chuvoso e início do período seco, entre maio e outubro de cada ano (Fig.1). Os municípios afetados foram Piancó (19 surtos) que apresenta uma altitude de $264 \mathrm{~m}$ e coordenadas geográficas de $07^{\circ} 11^{\prime} 52^{\prime \prime} \mathrm{S}$ e $37^{\circ} 55^{\prime} 44^{\prime \prime} \mathrm{O}$, Aparecida (2 surtos) com uma altitude de $224 \mathrm{~m}$ e coordenadas geográficas de $06^{\circ} 47^{\prime} 02^{\prime \prime} S$ e $38^{\circ} 05^{\prime} 13^{\prime \prime} \mathrm{O}$, Pombal (1 surto) que está situada à uma altitude de 184 metros e possui coordenadas de $06^{\circ} 46^{\prime} 12^{\prime \prime} S$ e $37^{\circ} 48^{\prime} 07^{\prime \prime O}$, São José de Espinharas (1 surto) que encontra-se à uma altitude de $208 \mathrm{~m}$ e coordenadas de 0650'49"S e 37 19'33"O e Patos (1 surto) que possui uma altitude de 242 metros e coordenadas geográficas de $07^{\circ} 01^{\prime} 28^{\prime \prime S}$ e $37^{\circ} 16^{\prime} 48^{\prime \prime O}$. Nos anos de 2008 e 
Quadro 1. Dados epidemiológicos e hemoparasitas identificados em 24 surtos de tristeza parasitária ocorridos no sertão da Paraiba no período 2007-2009

\begin{tabular}{|c|c|c|c|c|c|c|c|c|c|c|}
\hline \multirow[t]{3}{*}{ Surto } & \multicolumn{3}{|c|}{ Dados da propriedade } & \multicolumn{7}{|c|}{ Dados dos surtos } \\
\hline & \multirow[t]{2}{*}{ Município } & \multirow{2}{*}{$\begin{array}{l}\text { № to- } \\
\text { tal de } \\
\text { ovinos }\end{array}$} & \multirow{2}{*}{$\begin{array}{c}\text { Raça } \\
\text { predomi- } \\
\text { nante }\end{array}$} & \multirow[t]{2}{*}{ Mês/Ano } & \multirow{2}{*}{$\begin{array}{l}\text { № de bo- } \\
\text { vinos aco- } \\
\text { metidos (\% } \\
\text { morbidade) }\end{array}$} & \multirow{2}{*}{$\begin{array}{l}\text { № de mor- } \\
\text { tes (\% le- } \\
\text { talidade) }\end{array}$} & \multirow[t]{2}{*}{$\begin{array}{l}\text { Categoria } \\
\text { acometida }\end{array}$} & \multicolumn{3}{|c|}{$\begin{array}{l}\text { Hemoparasitas identificados } \\
\text { no sangue }\end{array}$} \\
\hline & & & & & & & & A. marginale & B. bigemina & Babesia sp..$^{b}$ \\
\hline 1 & Piancó & 20 & Mestiça ${ }^{a}$ & $8 / 2008$ & $\begin{array}{c}\text { Não } \\
\text { disponivel }\end{array}$ & $\begin{array}{c}\text { Não } \\
\text { disponivel }\end{array}$ & Adulta & & + & \\
\hline 2 & Piancó & 25 & Mestiça $^{a}$ & $6 / 2008$ & $5(20)$ & 0 & Adulta & + & & \\
\hline 5 & Piancó & 80 & Holandesa & $8 / 2008$ & $1(1,3)$ & 0 & Adulta & & + & \\
\hline 6 & Piancó & 26 & Nelore & $6 / 2008$ & $1(3,8)$ & $1(100)$ & Jovem & + & & \\
\hline 7 & Piancó & 20 & Mestiça ${ }^{a}$ & $6 / 2009$ & $2(10)$ & 0 & Adulta & + & & \\
\hline 8 & Piancó & 15 & Mestiça ${ }^{a}$ & $9 / 2008$ & $2(13,3)$ & 0 & Jovem & + & & \\
\hline 9 & Piancó & 30 & Mestiça $^{a}$ & $8 / 2007$ & $1(3,3)$ & 0 & Adulta & + & & \\
\hline 10 & Piancó & 25 & Mestiça ${ }^{a}$ & $9 / 2008$ & $1(4)$ & 0 & Adulta & + & & + \\
\hline 16 & Piancó & 29 & Mestiça $^{a}$ & $8 / 2009$ & $1(3,4)$ & $1(100)$ & Adulta & + & & \\
\hline 17 & Piancó & 15 & Mestiça ${ }^{a}$ & $9 / 2009$ & $2(13,3)$ & 0 & Adulta & + & & \\
\hline 18 & Piancó & 10 & Mestiça ${ }^{a}$ & $9 / 2009$ & $1(10)$ & 0 & Adulta & + & & \\
\hline 19 & Piancó & 17 & Mestiça ${ }^{a}$ & $9 / 2009$ & $1(5,9)$ & 0 & Adulta & + & & \\
\hline 20 & Aparecida & 87 & Nelore & $8 / 2008$ & $10(11,5)$ & $9(90)$ & Adulta & + & & \\
\hline 21 & Aparecida & 200 & Mestiça $^{a}$ & $7 / 2009$ & $1(0,5)$ & 0 & Adulta & + & & \\
\hline 22 & $\begin{array}{l}\text { S. J. } \\
\text { Espinhara }\end{array}$ & 120 & Mestiça ${ }^{a}$ & $7 / 2009$ & $7(5,8)$ & $5(71,4)$ & Adulta & + & & \\
\hline 23 & Pombal & 20 & Pardo Suiça & 07/2008 & $8(40)$ & $7(87,5)$ & Adulta & + & & \\
\hline 24 & Patos & 27 & Mestiça ${ }^{a}$ & $05 / 2009$ & $12(44,4)$ & $11(91,7)$ & Adulta & + & & \\
\hline
\end{tabular}

a Animais mestiços de raças zebuínas com Holandês e Pardo Suiço.

b Por questões logísticas, a espécie de Babesia não foi identificada nesses surtos.

2009, quando foram observados 23 dos 24 surtos (Quadro 1), observou-se um claro aumento no índice de chuvas na região estudada em relação ao ano de 2007 e à média do período 1996-2006 (Fig.2). Entre 1996 e 2006, a média de pluviosidade nos meses com maior abundância de chuvas (janeiro a maio) em Patos foi de 59,34 a 118,9mm mensais, valores próximos dos observados em 2007 . No entanto, nos meses de 2008 e 2009, a quantidade de chuvas mensais praticamente dobraram ou triplicaram, atingido valores máximos de 491,6mm para março/2008 e 641mm para abril/2009.

Nas propriedades de Piancó foram observados carrapatos nos animais durante o período chuvoso, todos os anos. Com a aplicação do questionário verificou-se a aplicação indiscriminada, sem critérios técnicos, dos banhos carrapaticidas nos bovinos. Todos os banhos eram por

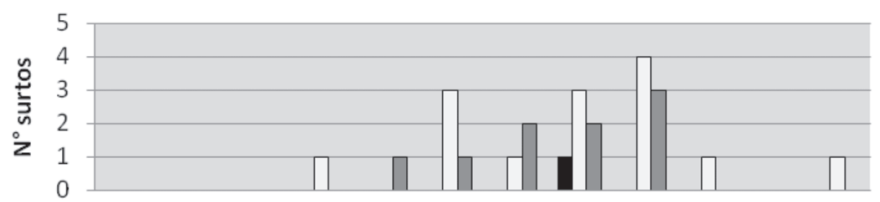

Mês JAN FEV MAR ABR MAI JUN JUL AGO SET OUT NOV DEZ - $2007 \quad \square 2008 \quad \square 2009$

Fig.1. Distribuição mensal dos surtos de tristeza parasitária bovina nos anos de 2007 a 2009. aspersão, com freqüência variável de duas vezes na semana, a cada oito dias, quinze dias ou a cada dois a três meses, porém sem um programa estabelecido de controle de carrapatos. O momento dos banhos era decidido sob critério subjetivo do criador, a despeito de um possível número "elevado" de carrapatos visíveis, porém sem quantificação estabelecida. Em apenas uma propriedade foi verificada a aplicação correta do volume de calda carrapaticida aplicada nos banhos (4-5L/animal); em algumas propriedades eram usadas bombas de $20 \mathrm{~L}$ para 13 a 40 animais adultos e em outras uma bomba de $10 \mathrm{~L}$ para 8 a 15 animais adultos.

No surto em São José de Espinharas ocorrido em um rebanho de vacas mestiças Holandês, o proprietário não tinha observado infestação por carrapatos em anos anteriores. Neste rebanho, foi relatada a introdução recente de animais com carrapatos provenientes da zona da mata Pernambucana, área tida como de estabilidade enzoótica. O surto de anaplasmose ocorreu no mês de julho, morrendo cinco animais, de um total de 120.

Em Aparecida ocorreram dois surtos de anaplasmose. O primeiro afetou um rebanho de corte com 87 bovinos da raça Nelore. Dez animais adoecerem e nove morreram em dez dias. No segundo surto, não foram vistos carrapatos nos bovinos; no entanto, durante a aplicação do questio- 


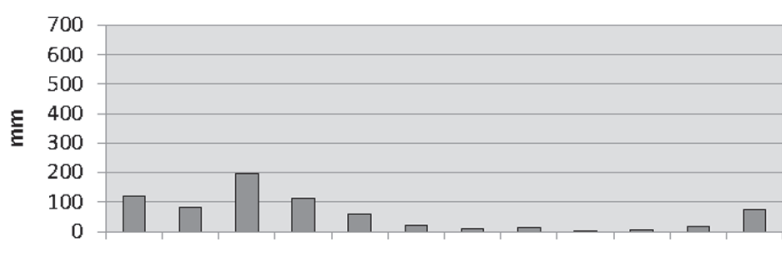

Mês JAN FEV MAR ABR MAI JUN JUL AGO SET OUT NOV DEZ $\square$ 1996-2006

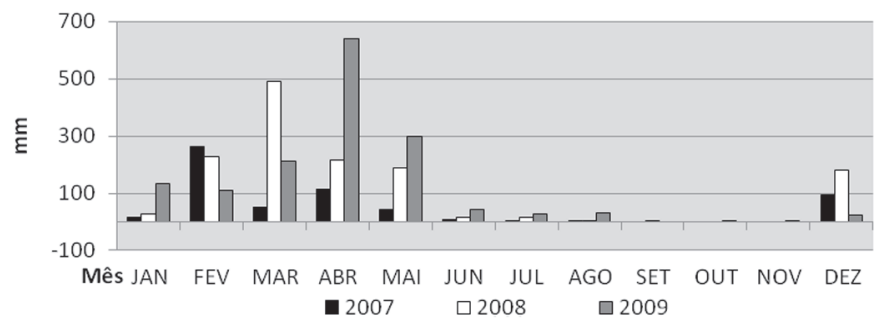

Fig.2. Acima observam-se as médias de chuvas mensais durante o período 1996-2006 no município de Patos, no sertão paraibano, e abaixo a quantidade mensal de chuvas nos anos de 2007, 2008 e 2009 no mesmo município (Fonte: Agência Executiva de gestão das águas do Estado da Paraíba).

nário foi informado que na propriedade era realizado o controle de carrapatos a cada oito dias, utilizando uma bomba de pulverização de 20 litros para banhar 25 animais. Ainda durante a visita foi informado que no período do surto havia a presença de numerosos tabanídeos na propriedade.

Na região de Patos, na bacia do Rio Espinharas, um surto de anaplasmose ocorreu em uma propriedade localizada nas margens do Rio Espinharas, onde morreram 11 animais de um rebanho leiteiro de 27 vacas cruzas zebuínos com Holandês e Pardo Suiço. Foi mencionada a ocorrência de carrapatos nos animais em anos anteriores. Durante a primeira visita, realizada em junho de 2008 , foi vista pouca quantidade de carrapatos. Os primeiros animais tinham adoecido em maio do mesmo ano e o rebanho era tratado com carrapaticidas a cada sete dias, numa proporção de dois litros de calda por animal. Neste surto foi realizada a necropsia de um dos animais acometidos, sendo observados macroscopicamente: icterícia, fígado cor de tijolo e baço aumentado. Em um surto de anaplasmose em Pombal, adoeceram oito bovinos e morreram sete de um rebanho de 20 vacas da raça Pardo Suiço.

\section{DISCUSSÃO}

Este trabalho confirma os resultados de um estudo anterior que definiu que no sertão da Paraíba ocorrem surtos de TPB no final da época de chuvas nas áreas de planaltos e serras, em áreas úmidas como as bacias do Rio do Peixe e Rio Piranhas e também em áreas irrigadas, como no município de Patos, em que há a formação de microclimas favoráveis à sobrevivência do carrapato (Costa et al. 2009). No entanto, chama a atenção que enquanto no período de 2000 a 2007 foram diagnosticados 14 surtos da doença (Costa et al. 2009), somente nos anos de 2008 e 2009 foram observa- dos 23 surtos. Esta maior freqüência está, aparentemente, relacionada à ocorrência de dois anos seguidos com chuvas abundantes, em valores atipicamente acima da média histórica para a região. Estes resultados sugerem que no sertão da Paraíba haja áreas de instabilidade enzoótica nas regiões mais altas do sertão e nas bacias dos rios perenes, e áreas livres, nas regiões mais secas e quentes do sertão. Mesmo nestas últimas, se bovinos com carrapatos são introduzidos no início do período de chuvas, podem ocorrer surtos no final do mesmo (Costa et al 2009), como possivelmente ocorreu na propriedade em São José de Espinhara no presente trabalho. No entanto, essa situação pode não se tornar estável, já que mesmo em áreas livres os carrapatos podem sobreviver durante anos chuvosos ou se manter em áreas de maior umidade em beiras de açudes e pastagens irrigadas. Por outro lado as áreas livres provavelmente aumentem nos anos mais secos, quando as condições de sobrevivência do carrapato são mais difíceis, e diminuam nos anos mais chuvosos, em condições favoráveis para a sobrevivência do vetor.

Os resultados encontrados neste trabalho mostram que, no sertão paraibano, casos clínicos de TPB são mais frequentes por anaplasmose do que por babesiose, fato que pode estar associado às formas de transmissão. $R$. microplus é o principal transmissor, mas a anaplasmose pode ser ainda transmitida por vetores mecânicos como tabanídeos. No caso dos tabanídeos, uma parasitemia maior que $0,3 \%$ favorece a transmissão mecânica por estes insetos (Kieser et al. 1990). Neste trabalho, o percentual de hemácias parasitadas por $A$. marginale observado foi muito elevado ( $1,8 \%$ a $80 \%)$ quando comparado ao que é visto por outros autores, onde dificilmente atinge 0,3\% (Kieser et al. 1990). As altas parasitemias certamente possibilitam a transmissão por vetores mecânicos, tais como mutucas, que são comuns em todas as propriedades do sertão no período chuvoso. Uma vez que haja bovinos sintomáticos com altas parasitemias no rebanho, a ocorrência de novos casos poderia ser potencializada pelos tabanídeos, comuns em todas as propriedades do sertão no período chuvoso. Essa hipótese ainda precisa ser testada, pois não existem dados publicados sobre esse assunto na região estudada.

Outra forma importante de transmissão é o uso coletivo de agulhas durante as vacinações e a aplicação de algumas medicações realizadas nos rebanhos, comuns nas criações de bovinos na região. No semiárido, a possibilidade de transmissão de $A$. marginale por esse meio, deve ser pesquisada para que possam ser tomadas as medidas preventivas adequadas. De qualquer forma é recomendável que nas áreas onde foi diagnosticado anaplasmose, não se utilize a mesma agulha para a administração coletiva de medicamentos e vacinas.

Semelhante ao que vem ocorrendo em outras áreas de instabilidade enzoótica (Farias 2007) a grande maioria de bovinos afetados são adultos. Bovinos de todas as idades são suscetíveis à infecção destes hemoparasitos, sendo que os animais jovens apresentam menor resistência à 
doença do que os animais adultos. A maior freqüência da doença em adultos se deve às condições climáticas do Sertão Paraibano que não permite a presença constante do carrapato e com isso, não há transmissão contínua dos agentes da TPB aos bovinos, principalmente em animais jovens, fazendo com que estes não desenvolvam imunidade específica adequada e tornem-se adultos sensíveis.

Também foi constatado neste trabalho que os animais mais afetados são bovinos das raças Holandês, Pardo Suíço e suas cruzas com animais da raça Gir, utilizadas para a produção de leite. Somente três surtos ocorreram em Bos taurus indicus, em gado das raças Nelore e Gir. Bovinos Bos taurus taurus são mais sensíveis a infestação por carrapatos que bovinos Bos taurus indicus, e as cruzas se situam em um nível intermediário de susceptibilidade (Payne \& Osório 1990).

A avaliação dos resultados deste trabalho e de um trabalho anterior (Costa et al. 2009) evidencia as dificuldades para se estabelecer medidas de controle e profilaxia da TPB no semiárido. Em áreas altas de serra (Piancó, por exemplo) e bacias de rios (Aparecida e Patos, por exemplo), onde o carrapato é mais freqüente, seria necessário que os produtores optassem por uma convivência com o mesmo, diminuindo a frequência dos banhos e deixando que os bezerros se infectem ainda nos primeiros meses de idade. Nesta situação os adultos somente deveriam ser tratados com carrapaticidas quando evidenciem uma infestação importante, que possa causar prejuízos ao animal. Segundo Junqueira (2010) a partir de 20-30 carrapatos por animal ocorrem perdas produtivas em animais adultos, portanto poderia recomendar-se o tratamento carrapaticida quando houvesse infestação de 10-20 fêmeas adultas. Os bezerros não deveriam ser banhados a menos que apresentassem infestações graves. Pelo contrário, é uma prática comum na região que os produtores comecem a banhar todos os animais imediatamente após detectar infestação por carrapatos adultos. Outras alternativas que deveriam ser consideradas, no futuro, são a utilização da premunição como forma de profilaxia para a babesiose e anaplasmose, (Gonçalves 2000), ou mesmo vacinas contra $R$. microplus, que por manter um número limitado de carrapatos nos animais favorece a estabelecimento da estabilidade enzoótica para babesiose e anaplasmose (Suarez et al. 2007). Em áreas onde o carrapato não consegue sobreviver de um ano para outro, a opção deveria ser por erradicar o mesmo da fazenda ou mantê-lo em quantidades muito baixas para que não ocorra transmissão. Neste caso é importante evitar a introdução de animais. parasitados, tratando-os eficientemente enquanto permanecem em quarentena antes de serem introduzidos no re- banho. É evidente que as possibilidades de êxito em ambos os casos são limitadas, pois permanece o risco de ocorrência de TPB.

\section{REFERÊNCIAS}

Costa V.M.M, Simões S.V.D. \& Riet-Correa F. 2009. Doenças parasitárias em ruminantes no semi-árido brasileiro. Pesq. Vet. Bras. 29(7):563-568.

Dreher U.M., Lehmann R.H., Meli M.L., Regula G., Cagienard A.Y., Srark K.D.C., Doherr M.G., Filli F., Hassig M., Braun U., Kocan K.M. \& Lutz H. 2005. Seroprevalence of anaplasmoses among cattle in Switzerland in 1998 and 2003: No evidence of an emerging disease. Veter. Microbiol. 107(1/2):71-79.

Eriks I.S., Stiller D. \& Palmer G.H. 1993. Impact of persistent Anaplasma marginale rickettsemia on tick infection and transmission. J. Clin. Microbiol. 31(8):2091-2096.

Farias N.A. 2007. Tristeza parasitária, p.524-532. In: Riet-Correa F., Schild A.L., Lemos R.A.A. \& Borges J.R.J. (Eds), Doenças de Ruminantes e Eqüinos. Vol.1. $3^{\text {a }}$ ed. Pallotti, Santa Maria, RS.

Gonçalves P.M. 2000. Epidemiologia e controle da tristeza parasitária bovina na região sudeste do Brasil. Cienc. Rur. 30(1):187-194.

Junqueira P. 2010. Garrapatas Boophilus en el ganado bovino: biologia, prevención y control.Disponível em <http: www. parasitosdel ganado.net/índex.php> Acesso em 21 de setembro de 2010.

Kessler R.H. 2001. Considerações sobre a transmissão de Anaplasma marginale. Pesq. Vet. Bras. 21(4):177-179.

Kieser S.T., Eriks I.S. \& Palmer G.H. 1990. Cyclic rickettsemia during persistent Anaplasma marginale infection of cattle. Infect. Immun. 58(4):1117-1119.

Kocan K.M., De La Fuente J., Blouin E.F. \& Garcia-Garcia J.C. 2004. Anaplasma marginale (Rickettsiales: Anaplasmataceae): Recent advances in defining host-pathogen adaptations of a tick-borne rickettsia. Parasitology 129(Suppl.):285-300.

Madruga C.R., Honer M.R., Andreotti M.R. \& Araújo F.R. \& Santarém V. 1993. Prevalência de Anaplasma marginale em três regiões do estado da Paraíba. Anais VI Congresso Internacional de Medicina Veterinária em Língua Portuguesa, p.350-352.

Payne R.C. \& Osorio O. 1990. Tick-borne diseases of cattle in Paraguai. I. Seroepidemiological studies on anaplasmosis and babesiosis. Trop. Anim. Health Prod. 1(22):53-60.

Sacco A.M.S. 2001. Controle/profilaxia da tristeza parasitária bovina. Comunicado Técnico 38, Embrapa Pecuária Sul, Bagé. 3p.

Sacco A.M.S. 2002. Controle de surtos de tristeza parasitária bovina. Circular Técnica 26, Embrapa Pecuária Sul, Bagé. 4p.

Souza J.C.P., Soares C.O., Scofield A., Madruga C.R., Cunha N.C., Massard C.L. \& Fonseca A.H. 2000. Soroprevalência de Anplasma marginale em bovinos na mesorregião Norte Fluminense. Pesq. Vet. Bras. 20(3):97-101.

Suárez Pedroso M., Mellor L.M., Valdez M., Souza R.M., Camargo A.J.R., Vargas N.C. \& Evanoff E.A. 2007. Control de las infestaciones de la garrapata Boophilus microplus en la ganadería Cubana y en regiones de latinoamérica con la aplicación del inmunógeno Gavac® dentro de un programa de lucha integral. Disponível em <http://www.corpoica. org.co/redectopar.asp> Acesso em 21 de setembro de 2010. 